\title{
Research on Prediction of Energy Storage Optimization Operation under the Power Internet of Things
}

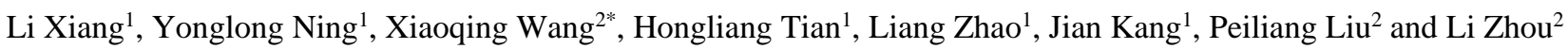 \\ ${ }^{1}$ State Grid N ingxia Electric Power C $0 ., \mathrm{L}$ td. \\ ${ }^{2}$ North China Electric Power U niversity
}

\begin{abstract}
The technological breakthrough of energy storage and the rapid decrease in cost make the application prospect of energy storage in power system more and more extensive, and will play an increasingly important role in the safe and efficient operation of power system. The optimal arrangement of energy storage load operation is conducive to the maximization of economic profit on the grid side, which is of great significance to the satisfaction of power demand of the distribution netw ork.
\end{abstract}

\section{Introduction}

Energy storage is an indispensable part in the construction of smart power grid and energy Internet. Research on energy storage prediction is conducive to promoting the consumption of energy storage and meeting the power demand of the Internet of things. The study of energy storage started early abroad. It is necessary to store energy to strengthen the grid and maintain load levels (H. Ibrahim,2007). Under the energy storage classification, the battery energy storage is more flexible to the load response of the power system. At present, the battery energy storage power station can give full play to its own function and gain benefits by improving the current electricity price system abroad ( $\mathrm{S}$. Bjarne,2013). In general, the existing research literature has carried out valuable research on various aspects of energy storage, which provides a theoretical basis for this paper. However, there is still room for further exploration in the prediction of energy storage load.

Based on battery energy storage, this paper studies the energy storage load operation under the influence of various factors such as electricity demand and electricity price of power grid in spot market.

\section{Energy Storage Load Operation Prediction Model}

The operation of energy storage load is affected by many factors, and its charging and discharging state is not only determined according to the energy demand of users, but also flexibly adjusted according to the economic and stability indexes of electricity consumption. The two main factors that affect the charging and discharging state of energy storage equipment are the electricity demand and the difference of electricity price in each period.
Energy storage is related to electricity demand and price of the power grid, and its operation is the result of balanced factors. Firstly, there is a significant correlation between electricity demand and time. When the off-peak load is low, the energy storage device stores energy; When the peak load is high, the stored electricity is released to meet the demand of other loads. Therefore, the operation of energy storage load is closely related to the load demand. Secondly, under market conditions, the price directly reflects the relationship between supply and demand, guiding the operation of energy storage load. When the electricity price is low, the energy storage device can store energy; When the electricity price is high, the energy storage device releases electricity.

In addition, the energy storage load operation can also play an important role in the auxiliary services of the power grid, such as can participate in frequency modulation, voltage regulation, standby, emergency power supply, improve the power supply quality, maintain the safety of the power grid, and so on.

In this paper, the prediction of battery energy storage participating in electric energy spot market load operation is divided into two stages: the first stage, based on the market clearing price, combined with the constraints of battery energy storage and storage capacity and output, preliminarily arranges the energy storage and discharge of energy storage; In the second stage, the operation prediction model of energy storage load is introduced to preliminarily determine the time set of energy storage and discharge of battery energy storage equipment, and the "loss factor" is introduced in the energy storage period to finally determine the energy storage and discharge capacity of each period and optimize the operation of energy storage.

\subsection{The first stage: preliminary operation scheme of energy storage load}

\footnotetext{
* Corresponding author: wangxiaoging0917@163.com
} 
In the electric energy spot market, battery energy storage devices arrange energy storage and discharge plans, and obtain benefits by making use of peak-valley price differences. The cost is mainly the storage cost, and the revenue is the electricity sales revenue.

In the process of battery energy storage and discharge, there are two constraint conditions: energy storage capacity constraint and output constraint.

It is assumed that the stored energy of battery energy storage can be converted into equivalent electrical energy. If the energy storage is $1 \mathrm{kWh}, 1 \mathrm{kWh}$ of electrical energy can be sold in the power market. Then the energy stored by the battery can be calculated within the time period of $\mathrm{T}$ as shown in Equation (1):

$$
E_{t}^{b}=E_{s}^{b}-E_{d}^{b}
$$

Where, $E_{t}^{b}$ is the energy stored by the battery at time $t, E_{s}^{b}$ is the total amount of energy stored by the battery at time t, and $E_{d}^{b}$ is the total amount of energy stored by the battery at time $t$.

Due to the constraint of battery capacity, energy storage or discharge cannot be sustained for a long time, so the trading volume of battery energy storage should meet the constraint, as shown in formula (2) :

$$
E_{\min } \leq \sum_{t=1}^{n} E_{t}^{b} \leq E_{\max }(n=1,2, \ldots, T)
$$

Where, $E_{\min }$ and $E_{\max }$ are respectively the minimum energy storage and maximum energy storage of the battery.

The storage capacity of battery energy storage is also restricted by the battery energy storage output, as shown in Equations (3) and (4) :

$$
\begin{gathered}
Q_{s, t}^{b} \geq C_{\min }^{b} \\
Q_{d, t}^{b} \leq C_{\max }^{b}
\end{gathered}
$$

Where, $C_{\min }^{b}, C_{\max }^{b}$ are the battery energy storage minimum efforts and maximum output.

In the first stage, based on the electricity market clearing price and the constraint conditions, the operation state of battery energy storage at each moment is preliminarily understood.

\subsection{The second stage: optimize the operation of energy storage load}

Based on the first stage, the running state of battery energy storage in each period is preliminarily obtained. In the second stage, an optimization model is constructed to maximize the profit and introduce the loss coefficient At this time, the objective function of battery energy storage is shown in Equation (5)

$$
\max R^{b}=\sum_{t=1}^{i}[L(t) \times P(t) \times Q(t)](i=1,2,3, \ldots 24)
$$

Where, $R_{b}$ is the profit gained in one natural day of battery energy storage, $L(t)$ is the loss coefficient,
$P(t)$ is the clearing price of the power market at time $t$; $Q(t)$ is the battery energy storage/discharge capacity. When energy storage is purchased, the value is negative, representing the cost; when energy release is sold, the value is positive, representing the income.

The revenue of energy storage device is the revenue from energy release minus the cost of energy storage and the cost of energy loss in the process of energy storage. In general, the participation of battery energy storage in the electricity market is economic only when the revenue of energy storage devices is positive. Therefore, in order to maximize the profits of battery energy storage when participating in market transactions, it is necessary to try to find a period in the electricity market where the price difference is large for energy storage and discharge.

Due to the introduction of loss coefficient, the calculation method of battery energy storage is shown in Equation (6) :

$$
\left\{\begin{array}{l}
E_{p}^{b}=\sum_{t \in T_{s}^{b}} Q_{s, t}^{b} \times L(t) \\
E_{g}^{b}=\sum_{t \in T_{d}^{b}}^{b} Q_{d, t}^{b}
\end{array}\right.
$$

Through the second stage of optimization, we can further determine the optimal storage capacity operation plan of battery energy storage.

\section{Analysis of examples}

In this section, a real-time market of simulated electric energy is established. The trading mode is bilateralcentralized, and the clearing is unified every hour. The market is unique in power consumption, and the supply side power supply includes 1 wind power supplier, 1 photovoltaic supplier and 1 battery energy storage supplier.

Each supplier provides power to meet the demand of the customer. The city's on-site electricity prices are subject to real-time supply and demand conditions and fluctuations. The subjects and specific information of each party in the electric energy market are shown in Table 1, 2 and 3 .

Table 1 Information of each market subject in the electric energy market

\begin{tabular}{|c|c|c|}
\hline suppliers & capacity & marginal cost \\
\hline Wind power & $1000 \mathrm{~kW}$ & 0 \\
\hline Photovoltaic power & $700 \mathrm{~kW}$ & 0 \\
\hline Energy storage & $1000 \mathrm{~kW}$ & A constant value \\
\hline
\end{tabular}

Table 2 Basic information of battery energy storage

\begin{tabular}{|c|c|c|}
\hline $\begin{array}{c}\text { Battery } \\
\text { capacity }\end{array}$ & $\begin{array}{c}\text { energy storage } \\
\text { efficiency }\end{array}$ & $\begin{array}{c}\text { combined } \\
\text { efficiency }\end{array}$ \\
\hline $3000 \mathrm{kWh}$ & $1000 \mathrm{~kW}$ & $75 \%$ \\
\hline
\end{tabular}


Table 3 Wind power and Photovoltaic power output in the electric energy market (unit: kW)

\begin{tabular}{|c|c|c|}
\hline time point & wind power & Photovoltaic power \\
\hline 1 & 45 & 0 \\
\hline 2 & 45 & 0 \\
\hline 3 & 45 & 0 \\
\hline 4 & 45 & 0 \\
\hline 5 & 45 & 0 \\
\hline 6 & 45 & 0 \\
\hline 7 & 45 & 30 \\
\hline 8 & 35 & 50 \\
\hline 9 & 30 & 60 \\
\hline 10 & 25 & 60 \\
\hline 11 & 24 & 65 \\
\hline 12 & 22 & 70 \\
\hline 13 & 20 & 70 \\
\hline 14 & 20 & 70 \\
\hline 15 & 20 & 65 \\
\hline 16 & 22 & 60 \\
\hline 17 & 24 & 40 \\
\hline 18 & 25 & 30 \\
\hline 19 & 35 & 0 \\
\hline 20 & 35 & 0 \\
\hline 21 & 40 & 0 \\
\hline 22 & 45 & 0 \\
\hline 23 & 45 & 0 \\
\hline 24 & 45 & 0 \\
\hline
\end{tabular}

The market clearing price curve is shown in Figure 1.

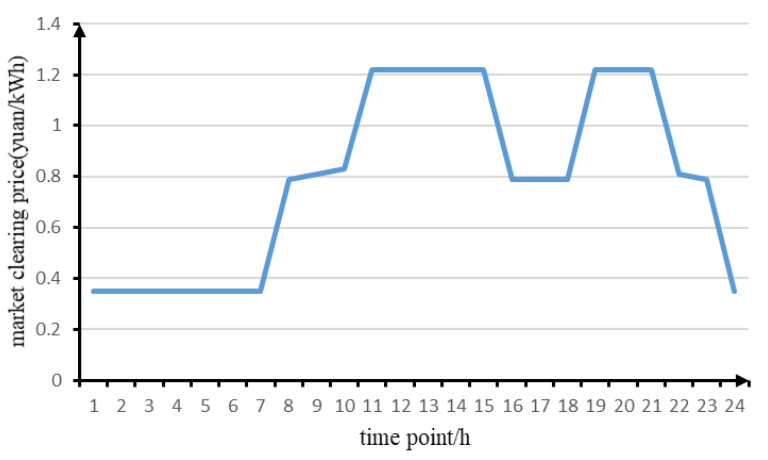

Fig. 1. Forecast daily market clearing prices at each time

At this point, the constraint condition is:

$$
\text { s.t. }\left\{\begin{array}{l}
-3000 \leq \sum_{t=1}^{i} Q(t) \leq 0(i=1,2,3, \ldots, 24) \\
-1000 \leq Q(t) \leq 1000
\end{array}\right.
$$

According to the market clearing price, the energy storage capacity and output constraint of battery energy storage are satisfied, and the operation scheme of energy storage equipment under the first stage is carried out. The results are shown in Fig. 2.

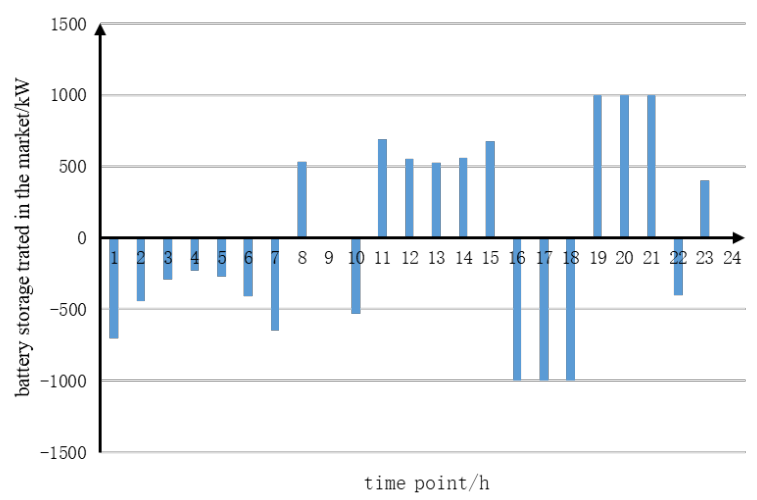

Fig. 2. Prediction of the first stage of battery energy storage

Fig. 2 shows the prediction of the operation of battery energy storage at each moment. The negative value represents the purchase of energy storage and the positive value represents the energy release and sale. In the second stage, the objective function is:

$$
\max R^{b}=\sum_{t=1}^{i}[L(t) \times P(t) \times Q(t)](i=1,2,3, \ldots 24)
$$

From this, the energy storage and discharge feasible sets of battery energy storage can be preliminarily obtained, as shown in Equations (9) and (10) :

$$
\begin{aligned}
& T_{s}^{b}=\{1,2,3,4,5,6,7,10,16,17,18,22\} \\
& T_{d}^{b}=\{8,9,11,12,13,14,15,19,20,21,23,24\}
\end{aligned}
$$

The loss coefficient should be introduced in the energy storage stage, so that the battery energy storage tends to choose the period when the price difference is large enough to make up for the loss of electricity. At this point, the purchase and sale of battery energy storage is recalculated.

After solving the model, the transaction quantity of each period of battery energy storage is obtained. The results are shown in Figure 3:

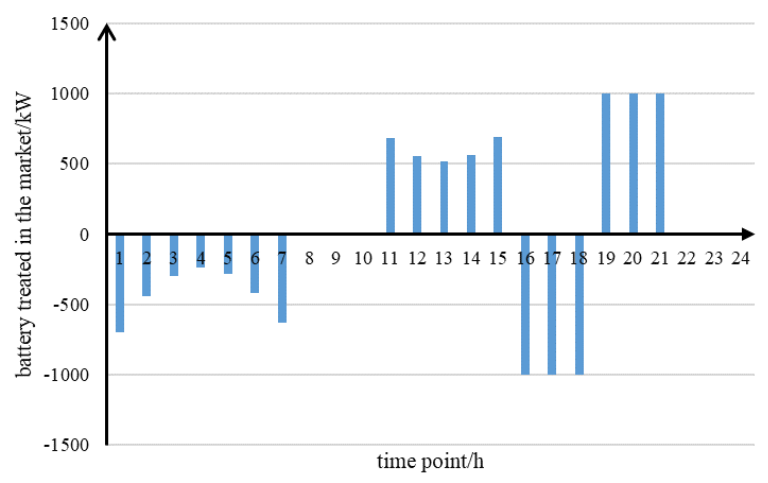

Fig. 3. Prediction of the second stage of battery energy storage

\section{CONCLUSION}

In this paper, a load prediction model based on the characteristics and influencing factors of energy storage equipment is proposed. The results of the example show that the model can be used to reasonably predict the operation of the energy storage equipment in each period of the day, reflect the situation of the energy storage 
participating in the electric energy spot trading market, and provide support for the optimization of the operation of energy storage load.

The operation of energy storage load affects the total power demand in the grid. The original electricity demand is deducted from the energy storage load to obtain the electricity energy demand that the distribution network needs to meet. The reasonable load arrangement of the energy storage equipment can effectively cut the peak and fill the valley and avoid the blocking of the transmission line. Smoother load curve can reduce the power loss in the transmission process, extend the service life of existing transmission and distribution facilities, improve asset utilization rate, and give full play to the effect of investment in transmission and distribution equipment.

\section{Acknowledgment}

The paper is supported by "Research on precise investment decision of distribution network based on the development demand of Ubiquitous Electric Internet of Things"(State Grid Ningxia Electric Power Company technology projects).

\section{References}

1. Hussein Ibrahim, Mazen Ghandour, Sabine Saad. Performance Index: A Simple Selection Method of A ppropriate Energy Storage for Specific A pplication. 2018, 171

2. Bjarne Steffen,Christoph Weber. Efficient storage capacity in power systems with thermal and renewable generation, Energy E conomics,2013,36.

3. D. Connolly,H. Lund,P. Finn,B.V. M athiesen,M. Leahy. Practical operation strategies for pumped hydroelectric energy storage (PHES) utilising electricity price arbitrage[]]. Energy Policy,2011,39(7).

4. Thang $\mathrm{Ngoc}$ Cong.Progress in electrical energy storage system:A critical review[J].Progress in Natural Science,2009,19(03):291-312.

5. Chi-Jen $Y$ ang,Robert B. J ackson. Opportunities and barriers to pumped-hydro energy storage in the U nited States[] ]. R enewable and Sustainable Energy Reviews,2011,15(1).

6. Savari George F,K rishnasamy Vijayakumar,Sathik Jagabar,Ali Ziad M,Abdel Aleem Shady H E. Internet of Things based real-time electric vehicle load forecasting and charging station recommendation.[]]. ISA transactions,2020,97. 